\title{
The Energy Expenditure of Sedentary Behavior: A Whole Room Calorimeter Study
}

\author{
Robert L. Newton Jr*, Hongmei Han, Theodore Zderic, Marc Hamilton
}

Preventive Medicine and Healthy Aging, Pennington Biomedical Research Center, Baton Rouge, Louisiana, United States of America

\begin{abstract}
It has recently been recommended that sedentary behavior be defined as sitting or reclining activities expending less than 1.5 metabolic equivalents (METs), which is distinct from the traditional viewpoint based on insufficient moderate-vigorous activity or formal exercise. This study was designed to determine the energy expenditure associated with common sedentary behaviors. Twenty-five African American adults (BMI 27.8 \pm 5.5 ) participated in the metabolic chamber study. Participants entered the metabolic chamber in the morning and their basal metabolic rate was estimated. They were fed breakfast and then engaged in four different sedentary behaviors sequentially, lasting 30 minutes each. The activities included reclining, watching TV, reading, and typing on a computer. In the afternoon, the participants were fed lunch and then the activities were repeated. The results show that the energy expenditure values between the morning and afternoon sessions were not significantly different $(p=.232)$. The mean energy expenditure of postprandial reclining (0.97 METs) was slightly, but significantly, lower than postprandial watching TV $(p=.021)$ and typing $(p<.001)$. There were no differences in energy cost (1.03-1.06 METs) between the seated (i.e., reading, typing, watching TV) sedentary activities. The energy expenditure of several common sedentary behaviors was approximately 1.0 METs in the postprandial state. The results support the conclusion that the average energy cost of common sedentary behaviors is narrowly banded around 1.0 METs in the postprandial state.
\end{abstract}

Citation: Newton RL Jr, Han H, Zderic T, Hamilton M (2013) The Energy Expenditure of Sedentary Behavior: A Whole Room Calorimeter Study. PLoS ONE 8(5): e63171. doi:10.1371/journal.pone.0063171

Editor: Reury F.P Bacurau, University of Sao Paulo, Brazil

Received February 25, 2013; Accepted March 28, 2013; Published May 3, 2013

Copyright: (c) 2013 Newton et al. This is an open-access article distributed under the terms of the Creative Commons Attribution License, which permits unrestricted use, distribution, and reproduction in any medium, provided the original author and source are credited.

Funding: This project was supported by the National Heart Lung and Blood Institute (K01 HL088723-01). The funders had no role in study design, data collection and analysis, decision to publish, or preparation of the manuscript.

Competing Interests: The authors have declared that no competing interests exist.

* E-mail: Robert.Newton@pbrc.edu

\section{Introduction}

There has been a recent emergence of studies assessing the health consequences of sedentary behavior (sitting), as distinct from too little exercise (sustained moderate-vigorous aerobic activity), and the physiology underlying these associations. [1-7] Evidence has been consistent in showing that large amounts of sedentary behavior are positively associated with the risk of coronary heart disease, [8] hypertension, [9] diabetes, [10] metabolic syndrome, [11,12] obesity, [13,14], mortality, [15,16] and some cancers. [16,17] From this background, insights about the seemingly simple issue regarding sitting energy expenditure are remarkably fundamental to many researchers. The plausibility that the observational associations are actually caused directly by sedentary behavior is strengthened by mounting physiological and molecular insights from experimental studies.[7,18-22].

These epidemiological and experimental findings have led researchers to define "sedentary" largely in terms of posture and concurrent energy expenditure as a helpful starting point. The issue has become so pressing that there was a recent consensus group recommending that journals require authors to define "sedentary" as sitting or reclining activity $\leq 1.5$ metabolic equivalents (METs). [23] Indeed, it is very well established that basal metabolic rate (BMR) is typically 0.7-1.0 METs, depending in large part on body composition. However, it is ironic that despite sitting being a ubiquitous behavior in all people, there are relatively few well-controlled studies actually assessing the energy expenditure of sitting.[24-32] This is out of balance with the robust physical activity literature describing exercise and other more demanding forms of lifestyle activity. [33,34] However, sitting (as one watches TV, reads, and types on a computer) alone may account for more than 9-10 hours of many individuals' waking days, and thus accurate assessment of the metabolic rate during sitting is essential in order to minimize errors in estimates of sedentary behavior [35].

Most of the studies that have assessed the energy expenditure of sitting behaviors[24-32] were focused on comparing basal metabolic rates to the energy cost of light or moderate intensity physical activity and included one or two sedentary behaviors. TV viewing has been frequently assessed in these studies, whereas other common sedentary activities, such as typing and reading, are less well studied. These studies also assessed sedentary behaviors over short periods of time, limiting their ability to detect spontaneous "fidgeting" and other simple behaviors requiring energy beyond sitting, which have been shown to increase energy expenditure. [36] In addition, metabolic carts that require the participant to be fixed to a hose and mouthpiece/facemask have typically been utilized to measure energy expenditure as opposed to less restrictive whole room calorimeters. Furthermore, most measured each activity only once, measurements were made exclusively in the fasted state, and most participants have been of European decent. These issues suggest that there are several important considerations for studies attempting to provide 
accurate estimates of sitting energy expenditure. First, quantifying sitting energy expenditure should be done at multiple times in the day (e.g. the morning and afternoon) because the percentage of time spent sitting is greatest during the workday in the modern chair-dominated office environments. [37] Second, since modern populations spend most of their time in the postprandial state (i.e., for $>5$ hours after meals), it is best to conduct estimates of sitting energy expenditure in the postprandial state. Third, investigators should use whole room metabolic chambers to estimate energy expenditure, whenever possible. This method allows researchers to simulate real-world activities in a more naturalistic setting. Fourth, researchers should assess sitting energy expenditure in at-risk populations in order to provide generalizability of the findings. Therefore, the present study will assess sitting energy expenditure in the morning and afternoon, in the postprandial state, and will utilize the metabolic chamber in a sample of African American participants. In these ways, the current study of sitting energy expenditure can play a significant role in advancing the field of inactivity physiology.

The present study was designed to determine the energy expenditure of common sedentary behaviors. All of the activities were conducted in a metabolic chamber over an 8 hour period. Our methodology involved a protocol where each person reclined/sat for extended periods of time while performing common sedentary activities. The intent was to determine the average energy expenditure of these sitting behaviors.

\section{Methods}

\section{Ethics Statement}

Each volunteer provided written informed consent and all procedures were approved by the Pennington Biomedical Research Center Institutional Review Board.

\section{Participants}

In order to be included into the study, participants had to a) selfclassify themselves as African American; b) be 18 years and older; c) be free of serious medical conditions; d) be free of any condition that would prevent them from engaging in physical activity, and e) weigh less than $250 \mathrm{lbs}$. Participants were primarily recruited through email and online advertisements, as well as through presentations at community events and newspaper advertisements.

\section{Measures}

Body Mass Index (BMI). Height and weight of each participant was measured in normal clothing, without shoes and socks. Standing height was measured to the nearest 0.1 centimeter (cm) by a wall-mounted stadiometer (Holtain Ltd., Crymych, Dyfed, UK). Weight was measured to the nearest 0.1 kilogram (kg) using an Indiana Scale Company model GSE 450 digital scale. Body mass index (BMI) was calculated by dividing the participant's weight in kilograms by the square of their height in meters $\left(\mathrm{kg} / \mathrm{m}^{2}\right)$.

Metabolic chamber. There were two metabolic chambers on site measuring $10^{\prime} \times 14^{\prime} \times 8^{\prime}(27,000 \mathrm{~L})$. [38] Once a month, the accuracy and precision of the respiratory chambers are assessed by 24-h propane combustion tests. The chamber software allows for the measurement of energy expenditure with high time resolution [38] by detecting changes in energy expenditure due to changes in activity level. The chamber responds to changes from one steady state of respiration to another and correctly averages repeated changes in respiration with periods less than 15 minutes $(<1.4 \%$ error for alternating $\mathrm{O}_{2}$ consumption levels).
Collected data was stored on a computer and the last 20 minutes of each 30 minute time block was averaged across the two repetitions ( $\mathrm{mL} \mathrm{O}_{2} / \mathrm{min}, \mathrm{kcal} / \mathrm{min}$ ), normalized to body mass ( $\mathrm{mL}$ $\mathrm{O}_{2} / \mathrm{kg} / \mathrm{min}, \mathrm{kcal} / \mathrm{kg} / \mathrm{hr}$ ). Excluding the first 10 minutes was necessary to ensure complete equilibration of energy expenditure traces between activity levels.

\section{Procedures}

Participants entered the chamber at 8:00 a.m. after a 12-hour fast (they were instructed not to consume any food or liquids, except water, after 8:00 pm the previous evening). Baseline resting energy expenditure was calculated while participants reclined on a bed for 30 minutes in the thermo neutral environment of the chamber. Participants were allowed 30 minutes to consume a $400 \mathrm{kcal}$ breakfast (16\% protein, 55\% carbohydrate, $28 \%$ fat), which was served immediately after the baseline period. The participants then engaged in the following activities for 30 minutes at a time: reclining/resting, watching TV, sitting at a desk, reading a book (sedentary activities), walking on a treadmill at a pace of 1.5 miles per hour (light intensity physical activity), and walking at 3 miles per hour on the treadmill (moderate intensity physical activity). Participants were then allowed 30 minutes to consume a $624 \mathrm{kcal}$ lunch (12\% protein, $45 \%$ carbohydrate, $43 \%$ fat) and each activity was repeated in the afternoon. Participants left the chamber at approximately 4:30 p.m. after completing all activities. The exact schedule for the metabolic chamber stay is displayed in Table 1. Although the treadmill walking was a part of the overall study design and ensured the subjects did have a modest amount of physical activity during the testing period, these results are extraneous to the purpose of the present investigation and will be presented elsewhere.

\section{Statistical Analysis}

Intraclass correlation coefficients (ICC) for each sedentary behavior were calculated for the morning and afternoon sessions. Mixed models ANOVA was used to compare energy expenditure amongst each of the sedentary behaviors between the morning and afternoon sessions. Mixed models ANOVA was also used to compare energy expenditure between the estimated basal metabolic rate and each sedentary activity utilizing Tukey-Kramer post-hoc adjustments. All statistical analyses were performed using SAS 9.2.

\section{Results}

\section{Demographics}

There were 25 participants $(40 \%$ male) who were recruited for the study. All participants completed the study (Table 2). The participants had an average BMI of 27.8 (5.5).

\section{Stability of Sedentary Activities}

The ICCs for each sedentary behavior were $0.77,0.77,0.81$ and 0.70 for reclining, watching $\mathrm{TV}$, typing and reading, respectively, when measured as $\mathrm{kcal} / \mathrm{kg} / \mathrm{hr}$. The values were essentially equal when measured as $\mathrm{mL} \mathrm{O} \mathrm{O}_{2} / \mathrm{kg} / \mathrm{min}$.

\section{Comparison of Morning and Afternoon Sessions}

When assessed as $\mathrm{kcal} / \mathrm{kg} / \mathrm{hr}$, the overall effect for activity type $(\mathrm{F}(3,59.6)=5.79 ; \mathrm{p}=0.002)$ was significant, but the effects of repetition $(\mathrm{F}(1,25)=1.50 ; \mathrm{p}=0.232)$, and the interaction of activity type by repetition $(\mathrm{F}(3,90.2)=2.36 ; \mathrm{p}=0.077)$ were not. The overall activity type effect indicates that there were differences in energy expenditure across the sedentary activities, and the interaction trend suggests that these may have differed across the 
Table 1. Schedule of activity during the metabolic chamber stay.

\begin{tabular}{|c|c|c|}
\hline 8:00 AM & Enter chamber & \\
\hline 8:30 AM & Energy expenditure data collection begins & Quietly resting on bed (preprandial reclining) \\
\hline 9:00 AM & Breakfast & \\
\hline 9:30 AM & Replicate 1 & Quietly resting on bed (postprandial reclining) \\
\hline $10: 00 \mathrm{AM}$ & & Watching TV \\
\hline 10:30 AM & & Typing at a desk \\
\hline 11:00 AM & & Reading at a desk \\
\hline 11:30 AM & & Treadmill walking $1.5 \mathrm{mi} / \mathrm{hr}^{\mathrm{a}}$ \\
\hline 12:00 PM & & Treadmill walking $3 \mathrm{mi} / \mathrm{hr}^{\mathrm{a}}$ \\
\hline 12:30 PM & Lunch & \\
\hline 1:00 PM & Replicate 2 & Quietly resting on the bed (postprandial reclining) \\
\hline 1:30 PM & & Watching TV \\
\hline 2:00 PM & & Typing at a desk \\
\hline 2:30 PM & & Reading at a desk \\
\hline 3:00 PM & & Treadmill walking $1.5 \mathrm{mi} / \mathrm{hr}^{\mathrm{a}}$ \\
\hline 3:30 PM & & Treadmill walking $3 \mathrm{mi} / \mathrm{hr}^{\mathrm{a}}$ \\
\hline 4:00 PM & & Quietly resting on bed ${ }^{\text {a }}$ \\
\hline 4:30 PM & Energy expenditure collection ends & \\
\hline
\end{tabular}

${ }^{\mathrm{a}}$ These data were not included in the current investigation.

doi:10.1371/journal.pone.0063171.t001

morning and afternoon. The lack of a repetition effect indicates that energy expenditure values between the morning and afternoon sessions were not significantly different. These same effects were seen when the data was expressed as $\mathrm{mL} \mathrm{O}_{2} / \mathrm{kg} / \mathrm{min}$. Therefore, the average value of the morning and afternoon sessions were utilized in subsequent analyses.

\section{Comparison of Sedentary Behaviors}

When assessed as $\mathrm{kcal} / \mathrm{kg} / \mathrm{hr}$, there was a significant effect for activity type $(\mathrm{F}(4,96)=47.3 ; \mathrm{p}<0.001)$. Post-hoc tests with TukeyKramer adjustments showed that the energy expenditure of preprandial reclining (estimated BMR) was significantly lower than each of the postprandial sedentary behaviors (all $\mathrm{p}$ values $\leq 0.001$ ). In addition, the $\mathrm{kcal} / \mathrm{kg} / \mathrm{hr}$ of postprandial reclining was significantly lower than watching $\mathrm{TV}(\mathrm{p}=0.021)$ and typing $(p<0.001)$. There were no differences between the seated (i.e. reading, typing, watching TV) sedentary behaviors. These results were identical when expressed as $\mathrm{mL} \mathrm{O}_{2} / \mathrm{kg} / \mathrm{min}$ and METs (Table 3).

The increase in oxygen consumption and energy expenditure from pre- to postprandial reclining was $\sim 18 \%(\mathrm{p}<0.001)$. To determine the effect of the sitting activities on energy expenditure independent of the feeding state we compared the postprandial reclining conditions to the postprandial seated conditions. The

Table 2. Characteristics of participants $(n=25)$.

\begin{tabular}{lllll}
\hline Variable & Mean & SD & Minimum & Maximum \\
\hline Age & 38.2 & 11.4 & 20.0 & 56.0 \\
Height (cm) & 168.5 & 7.2 & 155.1 & 182.2 \\
Weight (kg) & 79.0 & 16.7 & 56.3 & 113.3 \\
BMl & 27.8 & 5.5 & 19.9 & 41.1 \\
\hline doi:10.1371/journal.pone.0063171.t002 & &
\end{tabular}

Table 3. Energy expenditure of sedentary activities.

\begin{tabular}{|c|c|c|c|c|}
\hline Activity & $\mathbf{N}$ & $\begin{array}{l}\mathrm{mL} \mathrm{O}_{2} / \mathbf{k g} / \\
\min \\
\text { Mean } \pm S E\end{array}$ & $\begin{array}{l}\mathrm{Kcal} / \mathbf{k g} / \mathbf{h r} \\
\text { Mean } \pm \mathrm{SE}\end{array}$ & $\begin{array}{l}\text { METs } \\
\text { Mean } \pm \text { SE }\end{array}$ \\
\hline \multicolumn{5}{|l|}{ Preprandial } \\
\hline Reclining & 24 & $2.88 \pm 0.09^{\mathrm{a}}$ & $0.86 \pm 0.03^{\mathrm{a}}$ & $0.82 \pm 0.03^{\mathrm{a}}$ \\
\hline \multicolumn{5}{|l|}{ Postprandial } \\
\hline Reclining & 24 & $3.41 \pm 0.10^{b}$ & $1.01 \pm 0.03^{b}$ & $0.97 \pm 0.03^{b}$ \\
\hline Watching TV & 24 & $3.61 \pm 0.12^{c}$ & $1.08 \pm 0.04^{c}$ & $1.03 \pm 0.03^{c}$ \\
\hline Typing & 24 & $3.70 \pm 0.12^{c}$ & $1.11 \pm 0.04^{c}$ & $1.06 \pm 0.03^{c}$ \\
\hline Reading & 24 & $3.64 \pm 0.14^{b c}$ & $1.08 \pm 0.04^{b c}$ & $1.04 \pm 0.04^{b c}$ \\
\hline
\end{tabular}

Note: Values with different superscripts are significantly different from one another.

doi:10.1371/journal.pone.0063171.t003

oxygen consumption and energy expenditure of common seated activities was on average $7 \%(0.07 \mathrm{kcal} / \mathrm{kg} / \mathrm{hr})$ greater than the reclining posture $(\mathrm{p}<0.001)$. In Figure 1 , the average METs $(\mathrm{mL}$ $\mathrm{O}_{2} / \mathrm{kg} / \mathrm{min} / 3.5$ ) of each seated activity are reported in relation to the recommended 1.5 METs threshold for defining sedentary activity. [23].

\section{Discussion}

The data from the current study shows that the energy expenditure of several common sedentary behaviors when reclining or sitting ranges from 1.01 to $1.11 \mathrm{kcal} / \mathrm{kg}$ (body weight)/hr in the postprandial state. Our study is not the first to assess the energy expenditure of sitting behaviors. [24-32] These other studies have shown that the energy cost of sitting ranges from 0.99 to $1.14 \mathrm{kcal} / \mathrm{kg} / \mathrm{hr}$. [25,26,28,39,40] Multiple studies have specifically assessed the energy cost of TV viewing, and obtained 


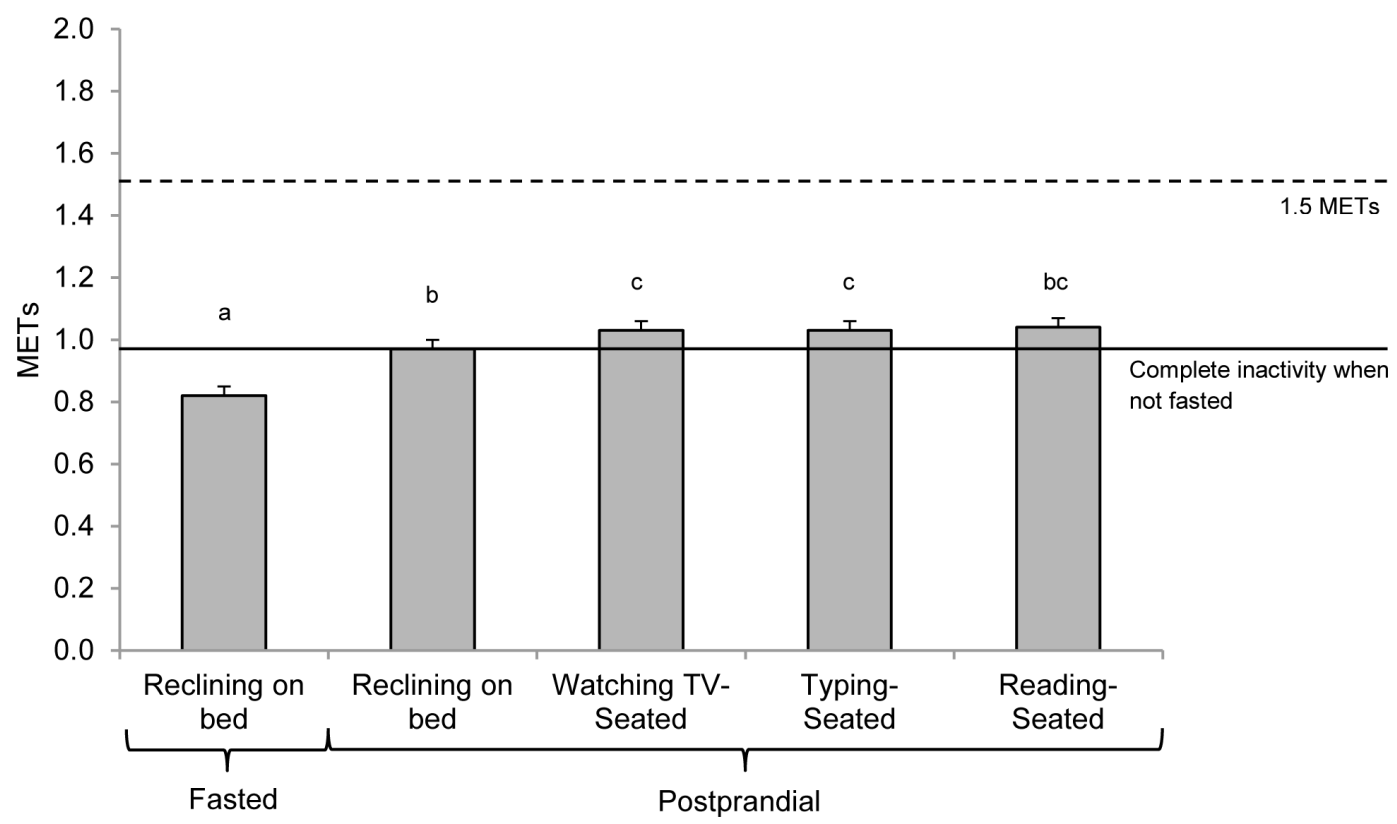

Figure 1. Oxygen consumption in MET units during sedentary behaviors. Each activity was measured for 30 minutes following breakfast and lunch. Bars represent the average MET value for each sedentary activity across breakfast and lunch. The dashed line represents the recommended MET value for sedentary behaviors. The solid line represents the average MET value for postprandial reclining. One MET is by definition is $3.5 \mathrm{ml} \mathrm{O}_{2} /$ $\mathrm{kg} / \mathrm{min}$. Postprandial seated activities on average required a $7 \%$ greater metabolic rate than postprandial reclining, and the average of the four sedentary behaviors in the postprandial state was 1.02 METs. Note: Values with different superscripts are significantly different from one another. doi:10.1371/journal.pone.0063171.g001

values of $0.93 \mathrm{kcal} / \mathrm{kg} / \mathrm{hr}$ [28], $0.97 \mathrm{kcal} / \mathrm{kg} / \mathrm{hr},[39], 1.03 \mathrm{kcal} /$ $\mathrm{kg} / \mathrm{hr}$ (the energy cost of playing a sedentary video game) [41], and $1.08 \mathrm{kcal} / \mathrm{kg} / \mathrm{hr}$. [40] which are similar, but on average slightly below our value of 1.08 . These findings show that the data from the current study is consistent with that of previous investigations. However, there are several important issues that the current study highlights that should be considered when interpreting the results of energy expenditure studies, including the stability of the energy expenditure estimates, the thermic effect of food, and the study sample.

The findings from the current study indicate that energy expenditure of sedentary behaviors is stable across the day, even when accounting for the postprandial rise. This was partially demonstrated by the moderate to strong ICGs which indicated that very little variability was due to the time of day. These correlations may have been slightly stronger if the energy cost of the meals was identical. This conclusion is also supported by the ANOVA data which demonstrated that there were no statistical differences in energy expenditure for the same activity measured in the morning and the afternoon. Though we did not measure these sedentary activities into the evening, it is likely that these values would not be significantly different from the obtained values. Therefore, our repeated measurement design allowed us to demonstrate the stability of the energy expenditure of sedentary behaviors. This is important because it will allow researchers to have confidence in estimating the energy cost of sedentary behaviors across the day.

The thermic effect of food cannot be ignored when interpreting these analyses. The thermic effect of food reaches a plateau 20-30 minutes after a meal and elevates energy expenditure $\sim 15-30 \%$ for at least 3 hours and then gradually decreases back to baseline levels by about 5 hours. [42,43] According to this model, the thermic effect of food should have had a similar effect on energy expenditure during the $0.5-2.5$ hour postprandial measurement period. Therefore, the greatest rise in energy expenditure should have occurred just after the meal, which would be during each of the reclining activities in both the morning and afternoon sessions. Despite the fact that there was an $\sim 18 \%-30 \%$ increase in energy expenditure from the basal assessment to the sedentary activities that was sustained across the two hour assessment of sedentary behaviors, the energy cost of reclining was shown to be significantly lower than that of the other sitting behaviors (likely due to the decreased cost of being supine). Therefore, although the thermic effect of food likely contributed to the increase in energy expenditure, it does not totally account for the increase in energy expenditure measured after the meal. Thus, the energy expenditure values in this study are a combination of the thermic effect of food and energy required to engage in the sedentary behaviors. In this way, we provide accurate estimates of an individual's energy expenditure in their usual state, sitting postprandially.

The examination of the postprandial energy expenditure during both the reclining and seated positions also provided an opportunity to discern how much of the increase in energy expenditure above BMR was due to sitting posture/activity per se and that due to thermic effect of food. The mean energy expenditure of the common seated activities was about $7 \%$ greater than reclining, or $0.07 \mathrm{kcal} / \mathrm{kg} / \mathrm{hr}$. This is an important calculation as it indicates that the average person expends only about $50 \mathrm{kcal} /$ day $(0.07 \mathrm{kcal} / \mathrm{kg} / \mathrm{hr} \times 9 \mathrm{hr} \times 79 \mathrm{~kg})$ above resting (reclining) and the thermic effects of food, during an average day with 9 hours of sitting.

The findings demonstrate that the energy expended during typical sedentary behaviors is very narrowly bounded around $\sim 1.0$ METs. It has been suggested that sedentary behavior be defined by activities expending 1.5 or less METs (Fig. 1). [23,44] Data from the current study suggests that, on average, common sedentary behaviors expend between 0.97 and 1.06 METs. Therefore, the data from the current study supports the 
proposition that activity expending $\leq 1.5$ METs can be safely defined as sedentary behavior. However, while 1.5 METs as a "sedentary threshold" may conservatively encapsulate all of the sedentary behaviors, it also may be too high and overlap with the lower threshold of energy expenditure defined as low-intensity physical activity (LIPA). LIPA are activities such as standing, walking, or stretching, and is generally regarded as activity expending more energy than sedentary behaviors, yet are below moderate intensity physical activity. Distinguishing between sedentary behavior and LIPA is important because engaging in LIPA may be a very specific recommendation for replacing sedentary time. $[45,46]$.

There are a number of strengths to the study. First, the most common forms of sedentary activities performed by adults were incorporated. Second, the study was conducted in a metabolic chamber. An advantage of the metabolic chamber method is that unlike the use of metabolic carts the volunteers are unencumbered and can move freely without wearing a device on the head and body, and energy expenditure can be measured comfortably for long epochs. Third, the study incorporated meals into the study design which presented the opportunity to assess the putative greater energy expenditure caused by sitting versus reclining in the most relevant nutritional conditions. Previous studies assessing the energy expenditure of activities have not incorporated this variable, decreasing the ecological utility of their studies. Fourth, long epochs were used. This allowed for fidgeting and other naturally occurring movements typical during sitting (e.g. weight shifts, scratching, limb movement to increase comfort, etc.) to occur. Given that sitting energy expenditure was close to 1.0 METS and within 7\% of reclining, there was no evidence that these movements have a significant impact on the total energy used to sit. Fifth, the same activities were conducted in both the morning and afternoon, allowing for an assessment of the stability of energy estimates to be obtained. More importantly, this study design allowed for an "average sitting energy expenditure" to be calculated and available for use as a reference for the growing field that focuses on sedentary (sitting) behaviors.

There are several potential limitations to the study. The study could suffer from order effects because the order of the sedentary activities was not randomized. However, the data show that the values are very similar both between behaviors and between the morning and afternoon sessions. Therefore, it is unlikely that physiologically meaningful differences existed between the energetics of reading, typing, and watching TV. The study can also be

\section{References}

1. Hamilton MT, Areiqat E, Hamilton DG, Bey L (2001) Plasma triglyceride metabolism in humans and rats during aging and physical inactivity. Int J Sport Nutr Exerc Metab 11 Suppl: S97-104.

2. Hamilton MT, Hamilton DG, Zderic TW (2004) Exercise physiology versus inactivity physiology: an essential concept for understanding lipoprotein lipase regulation. Exerc Sport Sci Rev 32: 161-166.

3. Hamilton MT, Hamilton DG, Zderic TW (2007) Role of low energy expenditure and sitting in obesity, metabolic syndrome, type 2 diabetes, and cardiovascular disease. Diabetes 56: 2655-2667.

4. Hamilton MT, Healy GN, Dunstan DW, Zderic TW, Owen N (2008) Too Little Exercise and Too Much Sitting: Inactivity Physiology and the Need for New Recommendations on Sedentary Behavior. Curr Cardiovasc Risk Rep 2: 292 298.

5. Tremblay MS, Colley RC, Saunders TJ, Healy GN, Owen N (2010) Physiological and health implications of a sedentary lifestyle. Appl Physiol Nutr Metab 35: 725-740.

6. Thorp AA, Owen N, Neuhaus M, Dunstan DW (2011) Sedentary behaviors and subsequent health outcomes in adults a systematic review of longitudinal studies, 1996-2011. Am J Prev Med 41: 207-215.

7. Zderic TW, Hamilton MT (2012) Identification of hemostatic genes expressed in human and rat leg muscles and a novel gene (LPP1/PAP2A) suppressed during prolonged physical inactivity (sitting). Lipids Health Dis 11: 137. thought to be limited in generalizability because it was conducted with an African American sample. In energy expenditure studies that have assessed the influence of ethnicity, there is some data to suggest that African Americans have a slightly lower resting metabolic rate compared to European Americans. [47-49] However, racial differences dissipate when accounting for organ sizes. [50] Data from the current study also suggest that concerns of limited generalizability are unwarranted. For example, similar values were found for BMR in the current study $(0.86 \mathrm{kcal} / \mathrm{kg} / \mathrm{hr})$ compared to others $(0.84-0.99 \mathrm{kcal} / \mathrm{kg} / \mathrm{hr})$. [25-27,39,41] Finally, we used MET units and energy expenditure per $\mathrm{kg}$ of total body weight to account for weight differences. The MET level of fasting or fed metabolic rate in the sedentary state (lying down or sitting) is likely dependent on BMI among other factors, and could shift the values up or down depending on body composition, which is beyond the scope of this paper.

Overall, the data from the current study provide energy expenditure values for common sedentary activities. The findings demonstrate that the energy expenditure for these activities does not differ across the day and that sedentary behaviors generally require minimally, but significantly, more energy compared to reclining. Participants were in the postprandial state for most of the activities and natural movements when sitting and reclining (e.g. fidgeting, leg shaking, shifting) were allowed to occur because the metabolic chamber was used. Therefore, the values of $\sim 1.0$ METs for sitting and reclining likely represent accurate values for typical sitting energy expenditure. Most importantly, our results support the notion that common seated activities are almost always well less than 1.5 METs. Researchers can utilize this data to estimate the energy cost of these common sedentary behaviors. In summary, regardless of the sedentary activity or time of day, and taking into consideration the thermic effect of food, energy expenditure averaged $0.97 \mathrm{MET}$ s when reclined and $\sim 1.04$ METs when seated. Therefore, we believe that our conclusion that sedentary behaviors are close to 1.0 METs is generalizable to similar populations, while we recognize the need for replication with more diverse samples to determine if more subtle differences exist.

\section{Author Contributions}

Conceived and designed the experiments: RLNJr MH. Analyzed the data: HH TZ. Wrote the paper: RLNJr HH TZ MH.

8. Li TY, Rana JS, Manson JE, Willett WC, Stampfer MJ, et al. (2006) Obesity as compared with physical activity in predicting risk of coronary heart disease in women. Circulation 113: 499-506.

9. Bassett DR Jr, Fitzhugh EC, Crespo CJ, King GA, McLaughlin JE (2002) Physical activity and ethnic differences in hypertension prevalence in the United States. Prev Med 34: 179-186.

10. Yancey AK, Wold CM, McCarthy WJ, Weber MD, Lee B, et al. (2004) Physical inactivity and overweight among Los Angeles County adults. Am J Clin Nutr 27: $146-152$

11. Ford ES, Kohl HW, Mokdad AH, Ajani U (2005) Sedentary behavior, physical activity, and the metabolic syndrome among US adults. Obes Res 13. 608-614.

12. Florez H, Silva E, Fernandez V, Ryder E, Sulbaran T, et al. (2005) Prevalence and risk factors associated with the metabolic syndrome and dyslipidemia in White, Black, Amerindian and Mixed Hispanics in Zulia State, Venezuela. Diabetes Res Clin Pract 69: 63-77.

13. Chau JY, van der Ploeg HP, Merom D, Chey T, Bauman AE (2012) Crosssectional associations between occupational and leisure-time sitting, physical activity and obesity in working adults. Prev Med 54: 195-200.

14. Thorp AA, Healy GN, Owen N, Salmon J, Ball K, et al. (2010) Deleterious associations of sitting time and television viewing time with cardiometabolic risk biomarkers: Australian Diabetes, Obesity and Lifestyle (AusDiab) study 2004 2005. Diabetes Care 33: 327-334. 
15. Dunstan DW, Barr EL, Healy GN, Salmon J, Shaw JE, et al. (2010) Television viewing time and mortality: the Australian Diabetes, Obesity and Lifestyle Study (AusDiab). Circulation 121: 384-391.

16. Matthews CE, George SM, Moore SC, Bowles HR, Blair A, et al. (2012) Amount of time spent in sedentary behaviors and cause-specific mortality in US adults. Am J Clin Nutr 95: 437-445.

17. Dallal CM, Brinton LA, Matthews CE, Lissowska J, Peplonska B, et al. (2012) Accelerometer-based measures of active and sedentary behavior in relation to breast cancer risk. Breast Cancer Res Treat 134: 1279-1290.

18. Bey L, Akunuri N, Zhao P, Hoffman EP, Hamilton DG, et al. (2003) Patterns of global gene expression in rat skeletal muscle during unloading and low-intensity ambulatory activity. Physiol Genomics 13: 157-167.

19. Bey L, Hamilton MT (2003) Suppression of skeletal muscle lipoprotein lipase activity during physical inactivity: a molecular reason to maintain daily lowintensity activity. Journal of Physiology 551: 673-682.

20. Zderic TW, Hamilton MT (2006) Physical inactivity amplifies the sensitivity of skeletal muscle to the lipid-induced downregulation of lipoprotein lipase activity. J Appl Physiol 100: 249-257.

21. Stephens BR, Granados K, Zderic TW, Hamilton MT, Braun B (2010) Effects of 1 day of inactivity on insulin action in healthy men and women: interaction with energy intake. Metabolism.

22. Dunstan DW, Kingwell BA, Larsen R, Healy GN, Cerin E, et al. (2012) Breaking up prolonged sitting reduces postprandial glucose and insulin responses. Diabetes Care 35: 976-983.

23. Sedentary Behaviour Research Network (2012) Letter to the editor: standardized use of the terms "sedentary" and "sedentary behaviours". Appl Physiol Nutr Metab 37: 540-542.

24. Levine JA, Schleusner SJ, Jensen MD (2000) Energy expenditure of nonexercise activity. Am J Clin Nutr 72: 1451-1454.

25. Kanade AN, Gokhale MK, Rao S (2001) Energy costs of standard activities among Indian adults. Eur J Clin Nutr 55: 708-713.

26. McAlpine DA, Manohar CU, McCrady SK, Hensrud D, Levine JA (2007) An office-place stepping device to promote workplace physical activity. $\mathrm{Br} \mathrm{J}$ Sports Med 41: 903-907.

27. Rao S, Gokhale M, Kanade A (2008) Energy costs of daily activities for women in rural India. Public Health Nutr 11: 142-150.

28. Lanningham-Foster L, Foster RC, McCrady SK, Jensen TB, Mitre N, et al. (2009) Activity-promoting video games and increased energy expenditure. J Pediatr 154: 819-823.

29. Lante K, Reece J, Walkley J (2010) Energy expended by adults with and without intellectual disabilities during activities of daily living. Res Dev Disabil 31: 13801389 .

30. Dos Anjos LA, da Mata Machado J, Wahrlich V, De Vasconcellos MT, Caspersen CJ (2011) Absolute and relative energy costs of walking in a Brazilian adult probability sample. Med Sci Sports Exerc 43: 2211-2218.

31. Swartz AM, Squires L, Strath SJ (2011) Energy expenditure of interruptions to sedentary behavior. Int J Behav Nutr Phys Act 8: 69.

32. Whybrow S, Ritz P, Horgan GW, Stubbs RJ (2012) An evaluation of the IDEEA activity monitor for estimating energy expenditure. Br J Nutr: 1-11.
33. Ainsworth BE, Haskell WL, Herrmann SD, Meckes N, Bassett DR Jr, et al. (2011) 2011 Compendium of Physical Activities: a second update of codes and MET values. Med Sci Sports Exerc 43: 1575-1581.

34. Ainsworth BE, Haskell WL, Whitt MC, Irwin ML, Swartz AM, et al. (2000) Compendium of physical activities: An update of activity codes and MET intensities. Med Sci Sports Exerc 32: S498-S516.

35. Matthews CE, Chen KY, Freedson PS, Buchowski MS, Beech BM, et al. (2008) Amount of time spent in sedentary behaviors in the United States, 2003-2004. Am J Epidemiol 167: 875-881.

36. Levine JA, Vander Weg MW, Hill JO, Klesges RC (2006) Non-exercise activity thermogenesis: the crouching tiger hidden dragon of societal weight gain. Arterioscler Thromb Vasc Biol 26: 729-736.

37. McCrady SK, Levine JA (2009) Sedentariness at work: how much do we really sit? Obesity 17: 2103-2105.

38. Nguyen-Duy TB, Nichaman MZ, Church TS, Blair SN, Ross R (2003) Visceral fat and liver fat are independent predictors of metabolic risk factors in men. Am J Physiol 284 E1065-E1072.

39. Steeves JA, Thompson DL, Bassett DR Jr (2012) Energy cost of stepping in place while watching television commercials. Med Sci Sports Exerc 44: 330-335.

40. Lyons EJ, Tate DF, Ward DS, Wang X (2012) Energy intake and expenditure during sedentary screen time and motion-controlled video gaming. Am J Clin Nutr 96: 234-239.

41. Lanningham-Foster L, Foster RC, McCrady SK, Jensen TB, Mitre N, et al. (2009) Activity-promoting video games and increased energy expenditure. J Pediatr 154: 819-823.

42. Keogh JB, Lau CW, Noakes M, Bowen J, Clifton PM (2007) Effects of meals with high soluble fibre, high amylose barley variant on glucose, insulin, satiety and thermic effect of food in healthy lean women. Eur J Clin Nutr 61: 597-604.

43. Crovetti R, Porrini M, Santangelo A, Testolin G (1998) The influence of thermic effect of food on satiety. Eur J Clin Nutr 52: 482-488.

44. Pate RR, O'Neill JR, Lobelo F (2008) The evolving definition of "sedentary". Exerc Sport Sci Rev 36: 173-178.

45. Healy GN, Dunstan DW, Salmon J, Cerin E, Shaw JE, et al. (2007) Objectively measured light-intensity physical activity is independently associated with 2-h plasma glucose. Diabetes Care 30: 1384-1389.

46. Spittaels H, Van Cauwenberghe E, Verbestel V, De Meester F, Van Dyck D, et al. (2012) Objectively measured sedentary time and physical activity time across the lifespan: a cross-sectional study in four age groups. Int $\mathrm{J}$ Behav Nutr Phys Act 9: 149.

47. Luke A, Dugas L, Kramer H (2007) Ethnicity, energy expenditure and obesity: are the observed black/white differences meaningful? Curr Opin Endocrinol Diabetes Obes 14: 370-373.

48. Weyer C, Snitker S, Bogardus C, Ravussin E (1999) Energy metabolism in African Americans: potential risk factors for obesity. Am J Clin Nutr 70: 13-20.

49. Sharp TA, Bell ML, Grunwald GK, Schmitz KH, Sidney S, et al. (2002) Differences in resting metabolic rate between white and African-American young adults. Obes Res 10: 726-732.

50. Javed F, He Q, Davidson LE, Thornton JC, Albu J, et al. (2010) Brain and high metabolic rate organ mass: contributions to resting energy expenditure beyond fat-free mass. Am J Clin Nutr 91: 907-912. 